\title{
The Application of Collective Ethics Charters: The Case of French Adventure Tour-Operators
}

\author{
Raphaël Dornier (corresponding author) \\ Isc Paris \\ 22 Bd du Fort de Vaux, 75017 Paris, France \\ Tel: 33-1-40-53-99-99 E-mail: rdornier@groupeisc.com \\ Vanessa Cothias \\ Weekendesk \\ 18 Rue Mozart, 92110 Clichy, France \\ Tel: 33-1-47-37-23-90 E-mail: nz_vanessa@hotmail.com \\ Leïla Loussaïef \\ Isc Paris \\ 22 Bd du Fort de Vaux, 75017 Paris, France \\ Tel: 33-1-40-53-99-99Ｅ-mail: lloussaief@groupeisc.com
}

\begin{abstract}
In recent years the tourism industry has seen the emergence of associations whose purpose is to encourage firms to behave in a more ethical fashion. In particular, ATR (Agir Pour un Tourisme Responsable: Action for responsible tourism) and ATES (Association pour le Tourisme Equitable et Solidaire: Association for equitable and interdependent tourism) represent an ever-larger number of tour operators who seek an increased commitment to sustainable tourism. Given this concern, and basing our research on the perceptions of adventure-tour operators top managers, we propose to explore to what extent the principles enunciated in these collective ethics charters have actually been applied within their organizations and "on the ground". An analysis of the observations we have collected shows that the application of these charters is still unsatisfactory on many levels, for reasons that are as much structural as they are economic or human. This leads to recommendations which we believe are likely to promote a better application of these charters in future.
\end{abstract}

Keywords: Tourism, Adventure-tour operators, Charters of ethics, Executives' perceptions

"Codes of ethics, organizational behavior, ethical scales and the relationship that exists between theoretical and applied ethics are some of the forces needed to help shape a new frontier of tourism research and scholarship" (Fennell \& Malloy, 1999 : 941). Following this guideline, the main objective of this article is to determine - in an exploratory way and basing our approach on the perceptions of top managers - the extent to which the principles set out in the collective charters of ethics adopted by the adventure travel industry are in fact applied by its member organizations. To address this question we first examine the ethical concerns at the organizational level in general, and within the tourism industry in particular. Secondly we describe our methodology, which is mainly based on face-to-face conversations with seven top managers from seven tour operators specializing in adventure travel, including six firms that subscribe to the ATR or ATES collective charters of ethics. Thirdly we discuss the limits on the application of ethical charters identified by the executives, with reference to the principles set out in the various charters. We then examine and explain the principal limits thus identified, and formulate recommendations designed to encourage a better application of these charters in future. We conclude by identifying the main contributions of our investigation, together with its principal shortcomings, and the further opportunities that it suggests.

\section{Ethics and the tourism industry}

This first section presents (i) an overall definition of ethics at the organizational level, (ii) a discussion of ethical problems in the tourism sector and (iii) a presentation of some studies analyzing ethics charters in the tourism industry.

\subsection{Ethics: an organizational approach}

Etymologically, ethics means "the science of morals". Some authors make no distinction between the two terms. Others however consider that there is indeed a difference since ethics is the domain of the particular (concerning an individual, a group, etc.) whereas morals are supposed to be universal (Comte-Sponville, 1994). As Lavorata (2009) 
points out, this distinction is widely accepted because it enables a clarification of the two concepts, thereby making ethics a compilation of all the good practices and behaviors that may or may not be accepted by the group. Mercier (2004) defines ethics as being "the thought that comes before the action. It is a search for identity that attempts, through an interior discussion, to distinguish the right and wrong ways to act; it thus seeks to achieve wise action". Ethics is then first of all a personal discussion about what is the right or wrong thing to do. It brings together our convictions and responsibilities and establishes criteria for judging the validity and the consequences of our actions.

The interest in ethics at the company level is close to the research stream on social responsibility of firms. This stream gave birth to many works over the last years, taking roots more particularly on the stakeholders theory (ex. : Clarkson, 1995 ; Donaldson \& Preston, 1995 ; Mitchell, Agle \& Wood, 1997). The concept of stakeholders can be defined as "any group or person that could impact or be impacted by the achievement of the goals of an organization". In a general meaning, this concept includes providers, customers, shareholders, employees, communities, political groups... (Freeman, 1984). In the tourism industry, stakeholders are especially numerous and diversified, and can be impacted, in a positive or negative way, by the activity of tourism organizations.

Certain authors locate the ethics of the firm among its executives (Moussé, 2002). Others however consider that there is "an organizational ethic" which can be defined as "the manner in which the firm incorporates its key values into its policies, practices, and decision-making processes" (Mercier, 2004). Thus a firm's ethics may be understood as all of the practices that are acceptable to society. By establishing practices that favor the development of the firm without harming society as a whole, the business operator then behaves in an ethical manner (Lavorata, 2009).

When it comes to marketing, the establishment of an ethical policy may run up against two problems. On the one hand the ethical policy may be based on genuine motives, but may also take on an opportunistic character, the ethical strategy thereby becoming a means for adding value to the brand (Lipovetsky, 1992). The ethical intentions then become a good way to commoditize the firm's image, and a weapon to use against the competition (Weil, 1990). On the other hand the ethical policy may appear to be in conflict with the marketing approach. In fact, the validity of marketing choices depends in large part on the ability of this discipline to exert a decisive influence on the public (Revat \& Flipo, 2003). In this regard, it is necessary to resolve the fundamental tug-of-war between the marketing objective (to boost consumption in order to create profits) and the brand's ethical ambitions (Laville, 2007).

\subsection{Ethical concerns in the tourism industry}

Today, ethics refers in particular to the recognition that certain technologic and scientific applications have negative impacts on our environment. It raises the question of individual and corporate responsibility concerning the habitats of species, pollution, and the expectancies of future generations (Jonas, 1990). In the tourism industry, this recognition is expressed as the need for the firm to be responsible. "Ethics is now a central feature of our everyday concerns, and is therefore becoming increasingly relevant to society and particularly to the tourism industry... Thus the challenges we face in the 21st century are those of the environment and sustainable development" (De Broglie, 2002).

The firm's responsibility may thus be viewed in the perspective of sustainable development, which has now given us sustainable tourism. This notion is based on the three pillars of sustainable development, while also incorporating the industry's own concepts, as follows:

$>$ Tourism that is supportable over the long term on the ecologic level: preserving natural resources and working to reduce the impacts of the tourism industry's activities on the environment.

$>$ Tourism that is fair on the social and human level: respectful of the cultural authenticity of host communities, preserving their traditional values, and thereby contributing to tolerance between nations.

Tourism that is viable on the economic level: ensuring viable economic activity over the long term.

All of these commitments must be incorporated into a sustainable, long-term approach. This conception is intended not only to limit the negative impacts of tourism on its destinations, but especially to improve the positive effects of tourism. We then see that the concepts of "tourism" and "sustainable development" need not be in opposition to each other.

In practice, however, being responsible in the tourism industry is not an easy matter. Short-term economic gain at the expense of longer-term cultural and environmental loss has been indeed commonplace (Hall \& Brown, 2008). According to these authors, this was the reality that negative social, cultural and environmental impacts of tourism - direct, indirect or induced — often outweighed its stated economic value. The WTO estimates that between 2010 and 2020 the tourism industry will continue to grow at about $6 \%$ per year. We can foresee the consequences that this great increase in the flows of tourists over the course of a single generation will bring about, if it is not 
controlled. In this regard the Guide du Routard (Backpacker's guide) lists the four main threats that weigh upon the ethical nature of the tourist industry.

On the economic level the income is often captured by middlemen (transportation companies, travel agencies, tour operators and hotel chains) thereby leaving little for the local populations. These generally fill insecure, seasonal positions. We estimate that 60 to $80 \%$ of worldwide tourism-industry income ultimately accrues to firms in the North. Poorly-controlled tourism also leads to changes in a country's social fabric. In Africa, a tour guide earns twice as much as a doctor, on average, and ten times as much as a farmer. One consequence of this imbalance is that increasing numbers of small farmers are abandoning the land to turn themselves into guides.

Moreover, as a result of the development of the tourism industry Human Rights are often flouted, in particular by the scourge of sex tourism. According to the UN, nearly $10 \%$ of international tourists choose their destinations based on "sexual opportunities", and according to the ACPE (Association Against Child Prostitution) sales generated by sex tourism amount to $12 \%$ of Thailand's GDP.(Note 1) The stipulations of international law are not always applied, and many countries turn a blind eye to child labor. According to the WTO, in 2008 more than 15 million children under the age of 18 were employed in the tourism sector.

On the cultural level we are seeing a "folklorization" of rites and cultures, which is leading to profound changes in local customs. In some cases the population is instrumentalized to generate additional tourism income.

On the environmental level the tourism industry is a contributor to global warming, mainly as a result of air travel. In addition, the strong appeal of destinations with a rich biodiversity is having a devastating impact. For example, coral reefs and ecosystems often fall victim to urbanization and the excessive use of coastal areas by tourists (damage to vegetation and aridity of the soils).

\subsection{Codes of ethics in the tourism industry}

As ethics and sustainable development has become a main issue in tourism, more and more tourism organizations have implemented codes of ethics. These codes are designed to set the ethical standard, guide, communicate and educate organizational members (Malloy \& Fennell, 1998 ; Payne \& Dimanche, 1996). From the late 1970s, mostly encouraged by external pressure, the tourism industry therefore began to establish guidelines for standards of behaviour. Professionals felt the need to monitor their conduct and commit to a "social contract" guiding moral behavior among businesses, tourists and the local community (Fennell \& Malloy, 2007). Three guiding principles for codes of conduct have been stated frequently: understanding the culture visited, respecting and being sensitive to the host population and treading softly on the host environment (Hall \& Brown, 2008).

A growing number of scholars therefore try to describe the current state of codes of ethics in the tourism landscape. The existence of a code is, of course, no guarantee of ethical practices. A code may be no more than a statement of a company's legal responsibilities and the conduct it expects from its employees and clients, rather than enumerating any ethical principles and aspirations that its management holds or aspires to (Hall \& Brown, 2008). Moreover, the compilation of codes of conduct in tourism may sometimes appear to be a means whereby company management can deflect responsibility away from itself towards its employees, or, more especially, to its tourist clients (Malloy \& Fennell, 1998). Fisher (2003) has distinguished between surface and deep approaches to ethics in understanding the difference between rhetoric and actual business practice. She notes that most businesses appear, either intentionally or otherwise, to adopt a surface 'self-interested' approach to ethics. Gordon and Townsend (2001) found operators which explained that their lack of ethics was due to tourist attitudes and health and safety liability.

Fennell and Malloy (1999) found that operators in the tourism industry cannot be considered homogeneous in terms of their ethical orientation. Specifically, their results show that ecotourism operators have a higher sense of ethical conduct than do their peers in other ventures. They explain partly this finding by the fact that ecotourism operators reported the use of codes of ethics in their business practices to a greater degree (95\%) than other tourism operators. Presumably then, the operators implementing daily codes of ethics are more likely to have a consistent ethical approach throughout their business operations.

Fennel and Malloy (2007) argue that tourism organizations should move to a more structured and functional view of ethics. Monitoring, auditing and reporting as therefore important elements of the formulation of codes of ethics. They also point out that, for a code of ethics to be truly implemented, there should be the compatibility between an organization's and individuals' value systems.

Having presented an overview of the ethical problems posed by the tourism industry, we now describe our methodology. Our main objective is to determine, for the adventure-travel sector, the extent to which the recommendations contained in collective charters of ethics are actually applied by the actors who subscribe to these charters. Our methodology is therefore essentially based on face-to-face interviews conducted with the top managers 
of adventure-tour operators, since these directors, especially in France, may be considered to be the "pioneers" of a tourism industry that places a higher value on ethics.

\section{Methodology}

We will describe the sector in question and the particular features of its "collective" commitment to a more ethical tourism, followed by our methods of data collection and analysis.

\subsection{The "formal" ethical commitment of adventure-tour operators}

There are about 400 tour-operators in France. Within this population, our study mainly addresses adventure-tour operators, because they are the ones best-known for their ethical commitments. There are about fifty of these in France. They are generally small private operators or associations. Some adventure-tour operators have agreed to group themselves into associations such as the ATR (Agir Pour un Tourisme Responsable: Action for responsible tourism) and ATES (Association pour le Tourisme Equitable et Solidaire: Association for equitable and interdependent tourism) aimed at promoting and monitoring the ethical character of their practices.

Operators generally make a distinction between adventure tourism and interdependent tourism, although the trips offered under these two themes may have certain similarities. These terms distinguish tours that are mainly "on foot" from tours that involve encounters and cultural immersion. However, we will include interdependent tourism in adventure tourism.

\subsection{Data collection and analysis}

Between April and June 2009 we conducted semi-direct face-to-face interviews with seven top managers from seven adventure-tour operators. The anonymity of their answers was guaranteed and the conversations were then retranscribed in order to carry out a content analysis. Of the seven tour operators, six subscribe to collective charters of ethics: four to the ATR Charter and two to the ATES Charter. The seventh does not subscribe to either one but has established its own charter of ethics.

Our interview guide was designed to highlight the executives' views of the ethical practices of their own organizations, with respect to the principles enunciated in the charters of ethics. We first asked them to express themselves concerning their own definition of ethics, the place of ethics in their organization, and their various ethical commitments. We then questioned them about the reasons that had caused them to subscribe to or avoid collective charters of ethics. They then had to explain to us how these charters were applied inside their organization. We attempted to determine more specifically whether, under this approach, there were commitments that had been particularly difficult to implement. Lastly, we asked them more specifically about the impact of the economic crisis on the application of the ethical commitments set out in the collective charters. One month later we went back to the managers interviewed, to confirm that the limits identified as a result of our content analysis did indeed correspond to the ones they had intended to describe during our conversation.

Our main interest is then to confirm, based on the executives' own words, whether the principles set forth in the charters are in fact applied, or whether on the contrary there are items that are still difficult to put into practice. To achieve this objective we will consider the commitments set out in each charter, and compare them with the limits described by the executives during our conversations.

\section{The limits of commitments: the managers' viewpoint}

Based on the managers' testimony, certain commitment criteria provided in the charters do indeed appear difficult to implement. Our presentation of the results is structured according to the charters of ethics subscribed to by the executives interviewed.

\subsection{The individual "custom" tour-operator's charter}

As regards the charter of his own organization, the quality manager interviewed identified only three limits concerning the actual application of the stated commitments:

- The weakness of the field checking during the crisis period: "We used to do a lot of checking on the ground. Since the crisis, this is no longer possible because there has been a reduction in the budgets for reconnaissance travel. We are trying to find ways to make up for this."

- The problem of "trusting" the service providers concerning their commitments: "We put the charter of ethics in the contract, and we leave time for our service providers to have it applied. But in spite of this we had the case of four hotels in Thailand that said they were following our policy but there was a report made by unidentified clients and we learned that these people were supporting sex tourism. We removed them from our itineraries." 
- Limited application as regards destinations: "For the time being we are concentrating our efforts on Asia. We are not yet taking action on all destinations, nor on all the itineraries that we offer. Not all destinations necessarily need them. "

\subsection{The ATES Charter}

The two managers who work for tour operators subscribing to the ATES Charter identified two major types of limits to its application: human limits and limits associated with inspection.

\subsubsection{Human constraints}

The managers emphasized the difficulties associated with the establishment of a relationship of trust concerning the consequences of development projects. Criterion No. 2 of the Charter states that "the operator selects partners involved in development projects that benefit the community". But since the tour operator does not always understand the true scope of these development projects, they may benefit only a few partners rather than the community, and this may ultimately undermine the operators' trust. The tour operator specializing in Latin America told us in this regard that "Latin America is like Africa: there are always personal or family interests between communities, which count for a lot. You have to know how to adapt to the local cultural conditions, and it's certainly not easy to gain their trust, especially from a distance". Reconnaissance trips are not always enough to gain an appreciation of how partners operate and thereby to better understand and manage the actual consequences of development projects.

The managers also mention the fact that commitments are basically still difficult to convey to clients. Criterion 5 states that "in designing its trips, the operator encourages encounters and exchanges." The operator must commit to favoring nights passed with inhabitants of the village, whereas the local living conditions are sometimes not what the clients are looking for. So, as the executive of an interdependent tour operator told us: "travelers find that the accommodation provided is too basic". Travelers are indeed welcomed and accommodated by the local population, but this gets them no more than a modest level of comfort which is sometimes not up to their needs. Moreover, these situations often lead to disputes. Nevertheless, according to this same executive, these persons were informed in advance of the accommodation arrangements: "even if we do it systematically, using brochures and our charter, it is often poorly understood by the people and the majority don't read it or they simply don't manage to grasp what the commitment involves...". The actual "on-the-ground" expression of ethical commitments still seems to be hard to communicate to clients, and that brings us to examine the most effective ways of informing the traveler and raising his/her awareness.

\subsubsection{Inspection constraints}

ATES chose a self-assessment system which covers both the organization and the product. It is based on a reference system that applies the principles of the charter. First, each member uses the table of criteria to make an assessment of its own structure and half of its destinations, selecting the ones most popular with its clientele. The grading employs a ternary system (0-1-2). A check is then carried out by the association's assessment committee, which includes members of the ATES and two executives from member associations. Three assessments are possible: total incorporation (overall grade greater than 12), partial incorporation (grade between 8 and 12), and pending (grade less than 8). However, this self-assessment system suffers from a lack of legitimacy and credibility. The two managers interviewed emphasized that the inspection may be biased by the human factor: "Everyone knows that there are rivalries between associations, so we come up against the problem of neutrality in an inspection by self-assessment. Some associations have been "kicked out" or alternatively encouraged, depending on the relationships of the managers. "So there is a risk of benefiting certain associations to the detriment of others, simply because of the existence of "relational networks". The credibility of such a system in comparison with a label certified by a State-recognized body, as with the ATR, may thus appear low in the eyes of clients, and even among professionals.

Lastly another limit was suggested, namely that the inspection mainly addresses the structure, field checks being limited: "ATES has opted for self-assessment [...] It really needs to find a way to give itself some credibility with the traveling public. It is true that self-assessment, like certification, is expressed in the form of an auditor who checks things internally, but the auditor is not going to go and check whether all the commitments are applied in all of the destinations".

\subsection{The ATR Charter}

The ATR Charter, according to the managers questioned, has various limits that affect its application, which are described below.

\subsubsection{Legislative and administrative constraints in countries of the "South"}

Criteria 1.5 and 1.6 of the ATR Charter require the operator to ensure proper respect for minimum decent social standards and to comply with local administrative and legal regulations However, in practice the inspection of 
partners is sometimes hindered by insufficient or even nonexistent legislation in the host countries, particularly regarding minimum social standards. A tour operator specializing in "customized" travel told us of seeing unethical traditional practices, for example at Pondicherry in India, in an attractive privately-run hotel where all the employees slept on the ground, in the entrance hall. To confirm that service providers fully comply with current legislation in their respective countries, this manager asks them to send him documents certifying that their activity is legal (tourism license, copy of their record in the commercial registry, and certificate of civil and professional liability) and to complete questionnaires about their practices. However, according to him, "this system has its limits: it's not an infallible inspection tool, but at least it's a tool for increasing awareness and for sending messages".

\subsubsection{Human constraints}

Criteria 1.9 and 2.4 require the tour operator to provide information for visitors and to make them aware of the need to respect the local population and the environment. The proper application of ethical commitments depends in large part on the tourists themselves, and therefore on their attitudes and behavior. But in spite of an increase in information from the tour operator designed to improve tourists' awareness of ethical problems, the operator cannot fully foresee or control the attitudes of its future clients. Generally speaking, tourists who purchase adventure tours are very concerned with protecting the environment. Nevertheless the manager of a tour operator specializing in hiking still frequently observes some abuses concerning respect for the population being visited, for example a tourist taking photos without the prior permission of the person photographed. Travelers are also sometimes stubborn when it comes to picking up after themselves in the desert. He emphasized the fact that "the good intentions that they start out with are often abandoned during the trip, in spite of having read the traveler's charter of ethics".

Moreover, the management of wastes and natural resources is still often misunderstood by the host populations. However, Criterion 2.1 sets out the following principle: "to apply a waste-management policy and a natural resource management policy, according to the sensitivity of the environment". The tour operator may nevertheless offer an integrated environmental management that covers all of the accommodation. This is the case, for example, for a tour operator specializing in "customized" trips who, in a Marrakech villa, provides personnel training and water management, sorting of wastes, and the use of biodegradable cleaning products. However, it runs up against the divergent concerns of its local partners, and says that "when we discuss it with our local service providers they say that these are the concerns of the rich countries, our concerns are different - but we try to raise their awareness anyway."

\subsubsection{Financial constraints}

Criterion 2.3 requires tour operators to promote the establishment of a policy for adjusting the flows of tourist to the scale of the destinations. The charter states that the flow of travelers should be limited to a group of 15 persons per trip for adventure travel, and 25 persons for cultural travel. But according to a tour operator that specializes in hiking, "this is a limit that goes against our need for profitability. When there is a fifty-person demand we don't turn them down, we get around the problem by splitting the group. There is a conflict between the restrictions imposed by the charter and the tour operator's need for profit, which requires a partial application of the commitment".

\subsubsection{Administrative and legal constraints}

Without outside help, the operators find it difficult to assess the true scope of the development projects that they support. However, Criterion 1.7 specifies that an operator must undertake to actively and financially support local development at the destinations. The manager of a tour operator specializing in hiking states on this subject: "we acknowledge that monitoring projects is not what we're good at and that we don't understand all the administrative and legislative parameters."

Criterion 4.2 sets out the following principle: "to have a formal inspection system within the firm". In this regard ATR has prepared a reference comprising 25 criteria included in the Consumer Code, all of whose points will be audited, in the case of certification candidates, by an independent body approved by the State (AFAQ-AFNOR). This is a mechanism for bringing clarity to the commitments, and in particular for putting an end to simple declarations of intentions. It meets the wish expressed by the member tour operators to establish a strong seal of approval that cannot be bought or received as a gift, but only acquired after a strict, independent examination. Accredited auditors travel to the firm's head office once a year. The inspection specifically includes an examination of administrative documents demonstrating the proper application of the reference criteria at each destination, and an examination of customer-satisfaction sheets. If the criteria are met the seal will be awarded for one year; if not, the operator may be allowed an extension. Ultimately, if the criteria are not met, the seal will be withdrawn. The ATR encourages and assists its members to become certified, but at the end of 2008 only five tour operators out of 
the network's 22 members were certified. The managers told us that the work required for certification represents a considerable cost for each organization: "the certification process is a demanding one, with lots of paperwork".

According to the executive of a tour operator specializing in interdependent and cultural travel, this significant financial cost prevents smaller operators from obtaining certification: "the cost of certification is substantial. (...) I think that's a pity because a number of small tour operators can't afford the cost and so they can't obtain this certification". The cost seems too high for tour operators who cannot benefit from this certification without help, whereas the certificate is a critical item in terms of credibility.

Finally, certification seems mainly limited to an internal inspection: "the reference system covers compliance with service commitments, especially their monitoring and management methods, but the inspection is primarily internal. We don't have the means to perform checks in the field, apart from reconnaissance trips".

\subsubsection{Communication constraints}

Criterion 6 stipulates that the operator must campaign for a fair and interdependent tourism and compliance with its principles, and undertake to promote the ATR. In any event it is in the operator's own interest to promote the network it belongs to, whether this is done in its brochures or in what it tells the traveler in person, and in general it does so systematically. The limit then comes from the publicity received from the ATR. In this regard a manager whose firm offers cultural and interdependent tours made the following statement: "there's something that troubles me; for example ATES, which has very good publicity, has been telling people that only immersion travel is interdependent. Firms like ours, which are responsible and interdependent, a little of both, with a corporate status, are left out of it to some extent, or ignored. Journalists have totally accepted that interdependent means ATES, and we're finding it very difficult to survive".

The executives' words have therefore identified a number of limits concerning the application of each of the charters. We will now discuss these limits, in particular from the standpoint of the experience of one of the authors, who worked for a tour operator subscribing to the ATR Charter. We will also attempt to formulate some recommendations designed to promote a better implementation of these charters.

\section{Discussion of results and recommendations}

In this section we will examine the main limits identified by the managers concerning the implementation of the charters of ethics, and then formulate some recommendations which should, in our opinion, strengthen the ethical character of tour operators' practices.

\subsection{Discussion of results}

\subsubsection{The shortcomings of an individual charter}

The exclusive use of an individual charter, even with an intensive commitment, may in our opinion prove inadequate in comparison to the use of a combination of individual and collective charters. When we break down the four themes of the tour operator's individual "custom" charter, we note that they are specific about the commitments they advocate. In fact, they recommend concrete actions such as the construction of a dam in Kenya to provide their own water supply to villages, or financial support to the climate-protection organization "My Climate" for the construction in Bali of plants for recycling organic wastes for compost, thereby creating jobs for 120 persons. These undertakings seem more practical than those in the ATR and ATES charters, which "content" themselves with promoting more general commitments without supplying details of their implementation "on the ground". We might then consider this tour operator to be more ethical, since it gives proof of its commitment. However, it seems that this is not necessarily so. It should for example be noted that each tour operator generally has its own individual charter and that, as a member of an association like ATR, it then "combines" its individual charter with the ATR's collective one. Consider the example of Voyageurs du Monde, which belongs to the ATR: in its individual charter it commits to eight key points that fall under the "Millennium Development Goals" adopted by the United Nations' Member States in 2000. These eight objectives are the following: to eradicate extreme poverty, to achieve universal primary education, to promote gender equality of the sexes and to empower women, to reduce child mortality, to improve maternal health, to combat HIV/AIDS, malaria and other diseases, to ensure environmental sustainability, and to develop a global partnership for development. Based on these commitments, the tour operator's charter commits it to providing financial support to the NGO UNITAID, which works to facilitate the international purchasing of drugs. It also undertakes to combat the sexual exploitation of children by asking its clients to tell them when they come across this problem, and by offering optional consciousness training to their personnel. For sustainable development it duplicates the words of the ATR Charter, and lastly, to combat global warming, it offers travelers an individual opportunity to financially offset their $\mathrm{CO} 2$ emissions by contributing to the $\mathrm{CO}$ 2Solidaire Association. 
It also seems reasonable to accept that the existence of an individual charter should imply that the tour operator be transparent about the financing of actions associated with this charter, whereas a collective charter automatically imposes such transparency. Thus the website of each tour operator that belongs to the ATR or ATES includes information concerning the financing of the interdependent and environmental actions undertaken, because this is an obligation "of transparency towards the client" instituted in each collective charter. But this is apparently not the case for the "custom" tour operator that does not subscribe to a collective charter: it gives no information on this matter. Moreover, as regards the content of the interview itself, while most of the tour-operator managers had provided us with numerical data or percentages concerning the proportion allocated to financing development projects, the manager of this tour operator was unwilling to say anything on this subject.

\subsubsection{The selection of solidarity funds}

Both collective charters state that that all subscribers are required to finance development projects. For the ATR Charter the amount of the contribution is decided every year by the members, at the General Meeting. The ATES Charter levies on its members a fee of $3 \%$ of the total price of each tour, and forwards it to a solidarity fund. In 2008, for a tour operator specializing in Latin America, this amounted to 23,000 euros for a total of 330 travelers. Each operator has its own development fund, which it uses to finance the projects it selects. This fund is normally designed for projects related to interdependent and environmental assistance for developing countries. But can it still be called interdependent when these funds are used to finance the construction of rammed-earth dwellings in Nicaragua? These dwellings are in fact used to accommodate a larger number of travelers, which is in the operator's interest but not necessarily that of the local population. On the other hand the construction of a well in Africa or support for a NGO helping street children in Venezuela, for example, is of great interest to the local population, and little interest to the travelers. Accordingly, it is important to properly distinguish between what is profitable for tourist development and what contributes to truly humanitarian projects, a distinction that is not really made in the charters.

\subsubsection{Technical constraints}

The implementation of certain measures which encourage responsible tourism may present technical problems. For example, equipment intended to reduce environmental impacts is sometimes hard to transport. Gas is generally employed in Amazonia for cooking because it avoids deforestation, but on the other hand its transport involves risks to the porters in the event of a fall or great heat. Moreover, the use of local products, particularly certain food and pharmaceutical products, for example in Africa, is not always easy, because of hygiene problems. Also certain essential commodities are sometimes unavailable locally. Lastly, note that in many countries there is little equipment for recycling wastes. Some towns in the Sahara have no incinerators, and tourist wastes, even when sorted, are ultimately buried in the ground or heaped up in the open.

\subsubsection{Economic constraints}

In a time of crisis tourists are more reluctant to travel, especially to distant destinations. They become increasingly sensitive to price. We must therefore question the ability of small tour operators to reconcile the maintenance of "ethical" prices that enable local service providers to secure a certain income, while at the same time making an adequate return for themselves. In particular, we note a new behavior on the part of tourists, who do not hesitate to "play the competition": asking for quotes from tour operators that offer similar services but have different ethical practices. The manager of a "custom" tour operator told us that "it's a bit like a market. They come with their quotes and for the same service being provided they choose the one that will give them the best rates. Clients are systematically asking sellers to give them an estimate".

Collective charters impose ethical standards that are liable to create additional costs, while at the same time the current economic situation encourages people to limit their expenses. As Flipo (2008) emphasizes, "respect for moral rules may run completely counter to the firm's interests, and it can be very expensive, to the point where it even leads to the disappearance not only of the firm that practices such respect, but of a whole economic sector". In addition, for the last few years travel providers have been in intense competition with large-scale distributors and online agencies. These organizations, of which there are many in the travel market, offer packages that are fairly similar to those of the tour operators, and at very competitive prices, but without the same ethical concerns. In a period of crisis for purchasing power, ethics may thus constitute to some extent a luxury that only organizations that have comfortable profit margins can permit themselves, which is not the case for the majority of "traditional" tour operators.

We can also raise questions about the fact that tour operators claim in their charters that they want to "commit sustainably to their partners", while at the same time the current demand is forcing them to offer tours to places that are closer and cheaper. We also note in recent years a certain boom in proximity tourism, which will probably 
continue. In terms of sustainable development it would be logical to favor travel over short distances, which has a lesser environmental impact. An association specializing in interdependent tourism in Latin America revealed that: "we're diversifying now; we're looking for authentic destinations in Europe. People have no money; they're taking shorter flights. We want to offer tours that are cheaper, shorter, and less polluting. Our reason for diversifying is mainly economic. So we're going to offer travel in Spain, especially in remote areas of Andalusia, and highly authentic tours in Northern Ireland and Italy".

\subsection{Recommendations}

In order to get around the limits identified by the managers, we will now present some recommendations that in our opinion are likely to encourage a better application of the collective ethical criteria on the part of the firms, the host countries, and their clients.

\subsubsection{Recommendations concerning associations that promote charters of ethics}

\section{- Acknowledging the importance of collective charters}

As we have seen earlier, compliance with the ethical commitments set out in an individual charter rests only on the goodwill of the firm, which constitutes an insufficient guarantee. Implementation of the charter thus has a good chance of being limited when set against other economic imperatives such as increasing sales, competitiveness, and profitability. On the other hand a collective commitment implies a greater control and the formulation of criticisms by other subscribers, which imposes a perpetual questioning of one's organization. For a proper application of the charter it therefore seems preferable, in our view, for firms to join an association that will guarantee compliance with it.

\section{- Creation of separate development funds}

ATES requires its members to establish a solidarity fund for development, but this involves both the comfort of the clientele and the development of the destinations. The first aspect mainly benefits the firms, while the second provides more benefit to the local population. This "pooling" inevitably distorts the visibility of how much is actually allocated to each. In our opinion it would be preferable to divide the development fund in two, with on the one hand an international solidarity fund (serving only for direct aid to the destinations), and on the other hand a tourism development fund intended to improve the comfort of the clientele and the professionalization of the service providers, so as to develop tourism in developing countries. Thus for example the tourism development fund would help the tour operators to build eco-lodges (ecological accommodation) in order to increase the volume of clients, or would allow them to offer training to the local guides so that they could acquire skills better suited to the needs of their clients. In particular this would eventually enable the proportion of local jobs to rise from $60 \%$ to $90 \%$ for the majority of tours. In Nepal, tour operators are generally forced to call on qualified European high-mountain guides to ensure the safety of travelers. The solidarity fund would be used to improve the living conditions of the local population, help them in their everyday life, and preserve the ecosystem.

\section{- $\quad$ Ethical commitments for the destinations}

Since the criteria of collective charters are still fairly general, it would seem desirable to adjust the terms of their application according to the various destinations. To do this it is necessary to have a detailed knowledge of the problems of each country and the needs of the local populations, hence the importance of considering the advice of an NGO with significant in-country experience. These NGOs therefore need to be systematically involved in decisions associated with the orientation and organization of interdependent actions. In particular, they should be consulted to define the projects to be undertaken, depending on the needs of each destination. Partnerships between tour operators and NGOs already exist, but they generally take the form of simple donations associated with the sale of the tour.

\section{- Establishment of shared databases}

It seems absurd that tour operators seeking to promote ethical practices continue to carry out their reconnaissance trips independently, and exclusively in their own interest. The explanation may be found in the fact that the ATR Charter provides for only limited exchanges of information between its subscribers. In fact, the organizations open their records to only one outside body, namely AFAQ-AFNOR, and the information collected for audit purposes is not released to other members of the association. In contrast, there are other associations at the international level that encourage a greater sharing of information among their members. They thereby enable the field data collected during reconnaissance trips to be pooled. The Travelife Association, for example, maintains a database on destinations that is shared by all its tour-operator members. However, very few French tour operators belong to it. This association has established the following system. Each member is first invited to perform a self-assessment, according to a table of criteria. Next, the employees of other tour-operator members will conduct a field audit to 
confirm the accuracy of the self-assessment. Once the audits of accommodation and service providers are complete, the candidate tour operator will be awarded a "bronze", "silver", or "gold" Ecological Label. Each item of assessment data may be consulted by members. In addition, a closer cooperation between tour operators, via a more systematic exchange of information covering a large number of areas, could strengthen their collaboration, which tends to be undermined in periods of crisis. We might also suggest, in this regard, that the "savings" generated by these collective databases could be redistributed to the local service providers as bonuses for a proper implementation of the charter.

\section{- More stringent conditions for becoming a member of the ATR}

At present, joining the ATR is not difficult. New members must hold a license or an official tourism approval as provided in the 1992 Act, and pay a subscription calculated on the basis of their latest sales figures. The tour operator is also asked to complete a document which contains a section on its structure, its management, and its organization, and a section corresponding to the criteria of responsible tourism. However, it states that if the requirements are not fully met, additional (unspecified) time will be granted to enable its structure to be made compliant. We believe that it would be desirable to set a deadline so that compliance is reached quickly, which would allow the new member's real level of involvement in responsible tourism to be assessed.

\subsubsection{Recommendations concerning tour operators}

\section{- Promote understanding between the tour operator and its local service providers}

To encourage a better understanding of the cultural realities while respecting the host countries, and to standardize working methods, the tour operator should, to a degree, promote the principle of expatriation. It would then encourage some of its employees to spend a limited time abroad, working with its foreign partners. These expatriates would thus more easily understand the customs and working methods of their partners, and be able to "justify" them to the tour operator. The tour operator's values and methods could then be progressively passed on, while allowing for the particular features of the local setting. This process could lead to a true relationship of trust between tour operators and service providers, and thereby limit the need for spot checks. The checking process would become essentially implicit and continuous. In addition, these expatriates could supply training for the service providers. However, it should be borne in mind that the service providers might see this person as a representative of the tour operator, seeking to impose its working methods. Lastly, the expatriate's salary should not be too high, so as not to compromise relationships with the local providers.

\section{- Provide more information to employees about ethical commitments}

The ATR reference specifies that all of the firm's employees must receive training concerning the commitments and implications of responsible tourism. But as far as we know, internal training has so far been insufficiently developed, and does not exceed 90 minutes once or twice a year. It seems essential to us to continue to advertise the approach in-house and to program regular one-hour meetings each week on this topic, so that perceptions of the objectives and implications of sustainable tourism are disseminated throughout the firm.

\subsubsection{Recommendations concerning destinations}

\section{- Seek a greater involvement of partners from the "South" in the production}

Different cultures, other concerns, a lack of mutual trust: all these limits on the implementation of charters of ethics were mentioned in conversations with the managers. Nevertheless, mutual understanding and genuine cooperation between tour operators and local service providers constitute the very foundation of the charters. In the field of tourism, tour operators often convey their own views of things, since the charters have been compiled by tour operators from the North with no real consultation with local partners. Their partners from the South often seek to receive a maximum number of travelers because they have a direct impact on the local economy. Moreover the Northern countries have a more long-term approach because for them the priority is to preserve the heritage of these countries as a source of major future revenue. The whole problem, then, is how to combine these two visions. This certainly demands a great deal of education and the creation of a real relationship of trust over the long term.

\section{- Broaden the commitments to include European destinations}

Owing to the current crisis, travelers increasingly prefer nearby destinations, especially in Europe. Consumers still want to travel, in spite of a drop in their purchasing power, but not as far away because air fares are making the trip too expensive. Adventure tour operators, forced to adapt to this new demand, are beginning to look for innovative tours in Europe. It would therefore be good if they were to offer environmental and interdependent commitments to these destinations. We found that one tour-operator member of the ATR with a European brochure is not proposing to participate in any interdependent or environmental actions for this destination. It might then be pertinent to 
suggest to travelers that they select the beneficiaries of any donations that they pay for, by highlighting the social and economic disparities or problems of certain cities.

\subsubsection{Recommendations concerning clients}

\section{- Raising the traveler's awareness}

It might be possible to suggest to travelers that they come to talk about their involvement and their travel experiences in meetings aimed at raising the awareness of future travelers concerning the realities awaiting them on the ground, as is done by ABM (Note 2) (Aventures du Bout du Monde: Wilderness adventures). This association, formed in 1988, has more than 4,000 members. Its goal is to encourage individual travel both near and far, in a simple natural style, while treating the countries visited with respect. To do this it promotes exchanges of information to enable everyone to assemble their own personal tour and, when they return, to describe their experiences. ABM maintains a documentation center and publishes a specialized journal: the "Globe-Trotters Magazine". Such exchanges of information between tourists could be promoted by the "ethical associations" themselves.

\section{Contributions, limits, and research opportunities}

A number of studies have already examined the principal limits of the ethical documents produced by tourist firms (vague commitments, incomplete methods of application, marginal position of institutions representing personnel and trade-union organizations, weakness of control structures, etc.). However, we thought it would be interesting to apply this type of analysis to the adventure-tour provider sector, which is currently growing, with emphasis on the views of its managers. This study has allowed us to reveal the dysfunctions of ethical charters, especially in regard to the implementation of planned commitments. We have shown that words are often difficult to translate into achievements on the ground, whether this is due to human, financial, or structural constraints. The main value of our analysis thus lies in the formulation of recommendations that can be exploited by firms seeking a greater commitment to ethical tourism within a collective approach.

Our study nevertheless has certain limits. Knowing that there are less than fifty adventure tour operators, we could have interviewed each of them in order to have data that were more reliable and more generally applicable. Moreover, this study is mainly based on the perceptions of managers. It might have been wiser to interview the various stakeholders in these charters, i.e., the travelers, the employees, and the local service providers. Not having the same interests as the managers, their views would certainly have been different, and other limits might have been identified. Lastly, the proposed recommendations do not consider the financial costs that they involve.

A suggested future line of research would be to learn the views of the managers regarding the governance of associations aimed at promoting ethical tourism. We believe that among the many factors liable to have an impact on the practical application of collective charters of ethics, the long-term development of the associations that "support" these charters is crucial. In particular, to what extent should the member organizations of the same ethics-oriented association have similar profiles and activities?

In any case, we should keep in mind, as noticed Fennell and Malloy (2007), that the formulation of codes of ethics is only a small piece in the puzzle of how to achieve sustainability and responsible corporate citizenship...

\section{References}

Clarkson, M. B. (1995). A Stakeholder Framework for Analysing and Evaluating Corporate Social Performance. Academy of Management Review, $20: 1,92-117$

Comte-Sponville, A. (1994). Valeur et Vérité. Etudes Cyniques Perspectives critiques, PUF.

De Broglie, E. (2002). La marque face à l'éthique : Guide du Développement Durable. Editions Village Mondial.

Donaldson, T. \& Preston, L. E. (1995). The Stakeholder Theory of the Corporation: Concepts, Evidence, and Implications, Academy of Management Review, $20: 1,65-91$.

Fennell, D.A., \& Malloy, D.C. (1999). Measuring the ethical nature of tourism operators. Annals of Tourism Research, $26: 4,928-943$.

Fennell, D. \& Malloy, D.C. (2007). Codes of Ethics in Tourism : Practice, Theory, Synthesis. Channel View Publications.

Fisher, J. (2003). Surface and deep approaches to business ethics. Leadership and organization Development Journal, 24 : 2, 96-101.

Freeman, R.E. (1984). Strategic Management : a Stakeholder Approach. Pitman, Boston. 
Gordon, G., \& Townsend, C. (2001). Tourism : putting ethics into practice. Teddington. UK Tearfund.

Hall, D., \& Brown, D. (2008). Finding a way forward : an agenda for research. Third World Quaterly, 29 : 5, 1021-1032.

Jonas, H. (1990). Le Principe Responsabilité. Une éthique pour la civilisation technologique. Flammarion.

Laville, E. (2007). L'entreprise verte. Editions Village Mondial.

Lavorata, L. (2009). Intégrer l'éthique dans l'entreprise - Un moyen d'impliquer les commerciaux et de les dissuader de la quitter. Décisions Marketing, 55, 53-63.

Lipovetsky, G. (1992). Les noces de l'éthique et du business. Problèmes économiques, 2276, 1-12.

Flipo, J. P. (2008). L'éthique managériale peut-elle n'être qu'un facteur stratégique ?. Revue Française de Gestion, $180,73-88$.

Malloy, D.C., \& Fennell, D.A. (1998). Codes of ethics and tourism : an exploratory content analysis. Tourism Management, $19: 5,453-461$.

Mercier, S. (2004). L'éthique dans les enterprises. La Découverte \& Syros.

Mitchell, R. K., Agle, B. R., \& Wood D. J. (1997). Toward a Theory of Stakeholders Identification and Salience: Defining the Principles of who and what really Counts. Academy of Management Review, 22 : 2, 833-886.

Moussé J. (2002). Ethique des affaires : liberté, responsabilité. Dunod.

Payne, D., \& Dimanche, F. (1996). Towards a Code of Conduct for the Tourism Industry : An Ethics Model. Journal of Business Ethics, 15, 997-1007.

Revat, R., \& Flipo J-P. (2003). Ethique et marketing: L'enquête. Cahiers de Recherche de l'EM Lyon, Juin.

Weil, P. (1990). Communication oblige. Editions d'Organisation.

\section{Notes}

Note 1. Information from www.acpe-asso.org.

Note 2. See the Aventures du Bout du Monde website: www.abm.fr 